\title{
Assessment of the possibility of the methane to methanol transformation
}

\author{
Beata Michalkiewicz \\ Szczecin University of Technology, Institute of Chemical and Environment Engineering, ul. Pułaskiego 10, \\ 70-322 Szczecin, Poland, e-mail: beata.michalkiewicz@ps.pl
}

\begin{abstract}
The methane to methanol conversion via esterification is an interesting method which makes it possible to eliminate the otherwise necessary phase of obtaining synthesis gas. On the basis of laboratory investigations mass balances for this process were determined. Preliminary assessment of the way of conducting the process and possibilities of practical applications of this technology was also made. It was pointed out that regardless of any possible modifications of methane to methanol conversion via esterification redundant sulfuric acid will always be produced during ester hydrolysis. Production of methanol from methane using this method can only be done when it is combined with producing other substances, which needs using $\mathrm{H}_{2} \mathrm{SO}_{4}$.
\end{abstract}

Keywords: methane, methanol, methyl bisulphate, Sankey diagram, mass balance.

\section{INTRODUCTION}

It has been recognized for a long time that a direct conversion process from methane to useful chemicals such as methanol would have many advantages over the indirect technology via synthesis gas ${ }^{1}$. In 1980 methane to methanol conversion via esterification method was patented ${ }^{2}$. In this method methane is oxidized to ester by means of strong acid at the presence of the catalyst. Then ester is hydrolyzed to methanol (Scheme 1).

methane + oxidizing agent + acid $\stackrel{\text { catalyst }}{\longrightarrow}$ methyl ester + reduced oxidizing agent

methyl ester + water $\rightarrow$ methanol + acid

Scheme 1

Several new catalyst systems have been reported which can be used for selective conversion of methane to esters: dichloro( $\eta$-2 $\left\{2,2^{\prime}\right.$-bipyrimidyl $\}$ platinum(II) in $20 \%$ oleum - ester yield $73 \%{ }^{3}, \mathrm{Hg}\left(\mathrm{OSO}_{3} \mathrm{H}\right)_{2}$ in $100 \%$ sulfuric acid - ester yield $43 \%{ }^{4}$, iodine and iodine compounds in $65 \%$ oleum - ester yield $92 \%{ }^{5}$.

When the reaction is carried in oleum or sulfuric acid methyl bisulphate is obtained ${ }^{3}$ :

$\mathrm{CH}_{4}+\mathrm{H}_{2} \mathrm{SO}_{4}+\mathrm{SO}_{3} \rightarrow \mathrm{CH}_{3} \mathrm{OSO}_{3} \mathrm{H}+\mathrm{SO}_{2}+\mathrm{H}_{2} \mathrm{O}$

Periana at al. suggested ${ }^{4}$, that although it is possible to separate methyl ester from the first step reaction media by commonly practiced methods such as flashing or distillation, there is in fact no need to isolate methyl ester since water can be added to the obtained solution. The product of the hydrolysis is methanol:

$\mathrm{CH}_{3} \mathrm{OSO}_{3} \mathrm{H}+\mathrm{H}_{2} \mathrm{O} \rightarrow \mathrm{CH}_{3} \mathrm{OH}+\mathrm{H}_{2} \mathrm{SO}_{4}$

Sulfur trioxide can be regenerated by oxidizing: $\mathrm{SO}_{2}+0.5 \mathrm{O}_{2} \rightarrow \mathrm{SO}_{3}$

The reactions (1) - (3) can be combined to give the net reaction:

$\mathrm{CH}_{4}+0.5 \mathrm{O}_{2} \rightarrow \mathrm{CH}_{3} \mathrm{OH}$

In this reactions (1) - (3), sulfuric acid functions as an oxygen-atom transfer reagent. The net transformation of the established step is the selective oxidation of methane to methanol with molecular oxygen. If the above described process were applied to methanol production, only methane and oxygen would have to be provided as substrates. Other reacting substances would be regenerated. According to the authors this technology would produce no waste.
The aim of this paper was preliminary assessment of the methane to methanol conversion via esterification and its possible practical applications.

\section{EXPERIMENTAL}

The investigated process consisted of two stages: methane esterification and hydrolysis of the obtained ester to methanol. Esterification was carried out at $160^{\circ} \mathrm{C}$, under methane pressure of $4.5 \mathrm{MPa}$ in an autoclave (volume $\left.0.25 \mathrm{dm}^{3}\right)$ containing oleum $\left(25 \mathrm{wt} . \%\right.$ of $\left.\mathrm{SO}_{3}\right)$. The esterification was described in detail in ${ }^{6}$. Platinum chloride (IV) was used as the catalysts of the process. The oleum volume was varied from $0.05-0.2 \mathrm{dm}^{3}$. Methyl bisulfate and carbon dioxide were obtained as products of the esterification. Methyl bisulfate was analyzed quantitatively by ${ }^{13} \mathrm{C} \mathrm{NMR}$.

Methanol was obtained by mixing with water in two different ways. First, it was produced in the method proposed by Periana et. al ${ }^{2-4}$ i.e. by adding water to the postreaction solution of esterification process. Second, methyl bisulfate was educed by means of membrane distillation and later hydrolyzed. These methods were described in detail in ${ }^{7,8}$.

Methanol and carbon dioxide were analyzed qualitatively by gas chromatography.

The yield of the methyl bisulfate was defined by the equation:

$\alpha_{\mathrm{CH}_{3} \mathrm{OSO}_{3} \mathrm{H}}=\frac{\mathrm{n}_{\mathrm{CH}_{3} \mathrm{OSO}_{3} \mathrm{H}}}{n_{0, \mathrm{CH}_{4}}} \quad 100 \%$

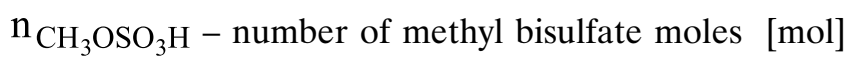

$\mathrm{n}_{0, \mathrm{CH}_{4}}$ - number of methane moles at the beginning of the reaction [mol]

\section{RESULTS AND DISCUSSION}

The oleum volume was varied in the experiments but because of the initial methane pressure was the same, the number of methane moles was varied as well. Figure 1 shows plot of the yield of the methyl bisulfate vs. volume of the oleum and number of moles of the methane at the beginning of the process. There is no the other product $\mathrm{CO}_{2}$ in the Figure 1 because the selectivity of the ester 
was more than $99 \%$. When the volume of the oleum (liquid reaction mixture) is larger the yield of the methyl bisulfate is raising. One can thing the volume of oleum suppose to be the largest.

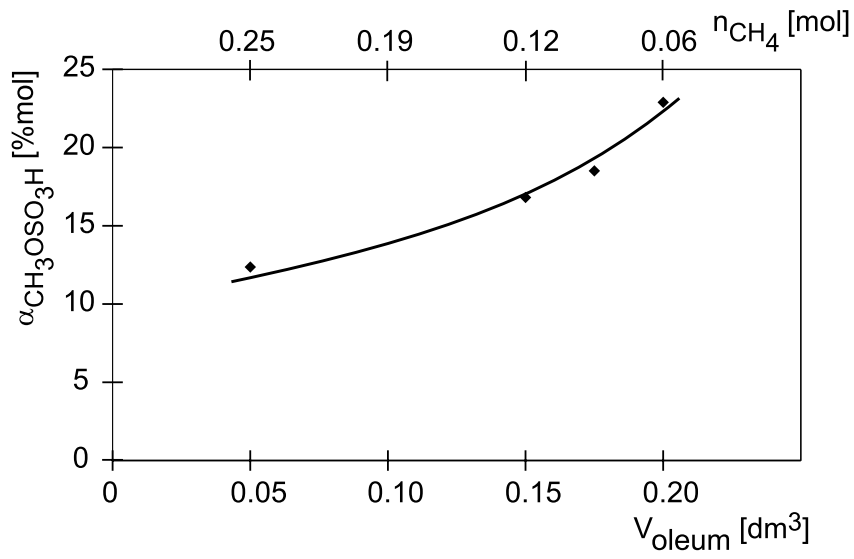

Figure 1. The yield of the methyl bisulfate vs. volume of the oleum and number of moles of the methane at the beginning of the process. Catalyst $\mathrm{PtCl}_{4}-0.0015$ $\mathrm{mol} \cdot \mathrm{dm}^{-3}$, initial methane pressure $4.5 \mathrm{MPa}$, oleum $-25 \%$ wt $\mathrm{SO}_{3}$, temperature $160^{\circ} \mathrm{C}$, time $2 \mathrm{~h}$

Figure 2 shows plot of the concentration of the methyl bisulfate in the reaction mixture vs. volume of the oleum and number of moles of the methane at the beginning of the process.

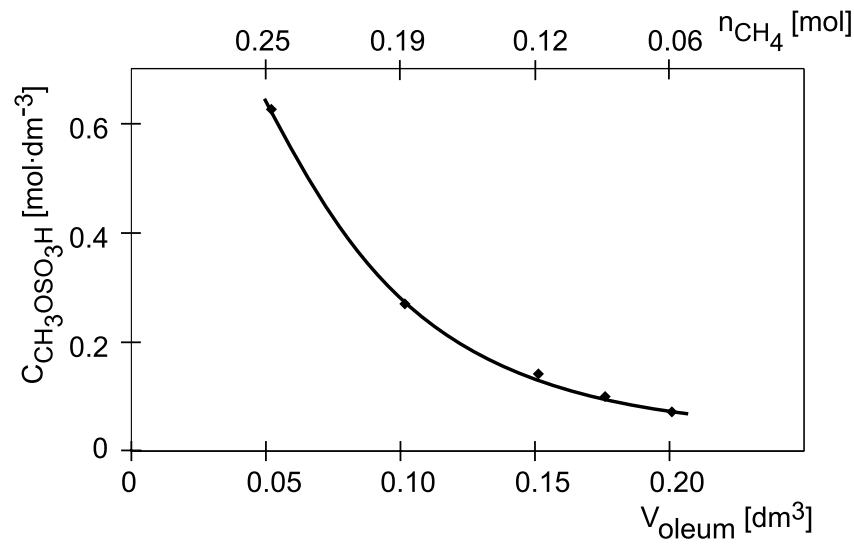

Figure 2. The concentration of the methyl bisulfate vs. volume of the oleum and number of moles of the methane at the beginning of the process. Catalyst $\mathrm{PtCl}_{4}-0.0015 \mathrm{~mol} \cdot \mathrm{dm}^{-3}$, initial methane pressure $4.5 \mathrm{MPa}$, oleum $-25 \%$ wt $\mathrm{SO}_{3}$, temperature $160^{\circ} \mathrm{C}$, time $2 \mathrm{~h}$

On the basis on Fig. 2 was found that the large volume of oleum supposed to be not favorable. The mass of the reaction mixture is preferred to be the smallest and the methyl bisulfate concentration should to be the highest. According this criterion the best results were obtained when the oleum volume was equal $0.05 \mathrm{dm}^{3}$ and then umber of moles $\mathrm{CH}_{4}-0.25$. The methyl bisulfate yield was equal to $12.4 \%$, selectivity $99.8 \%$.
On the basis of the best results the mass balance was made. The results of the calculations are presented in Table 1. In the presented calculations the mass of $\mathrm{H}_{2} \mathrm{SO}_{4}$ stands for sulfuric acid (VI) with $100 \%$ concentration, and the mass of $\mathrm{SO}_{3}$ denotes free sulfur trioxide dissolved in the acid.

In order to achieve a high yield of $\mathrm{SO}_{2}$ to $\mathrm{SO}_{3}$ oxidation amounting to $99.5 \%$ the content of $\mathrm{SO}_{2}$ in the gas solution should be approximately $15 \%{ }^{9}$. This required $147 \mathrm{~kg}$ of oxygen. As a result $72 \mathrm{~kg}$ of regenerated sulfur trioxide can be obtained. Hence, for every $100 \mathrm{~kg}$ of obtained methyl bisulphate not only $15 \mathrm{~kg}$ of methane and $34 \mathrm{~kg}$ of oxygen, but also $72 \mathrm{~kg}$ of $\mathrm{SO}_{3}$ should be provided, despite the fact that sulfur trioxide obtained from $\mathrm{SO}_{2}$ oxidation is returned to the reactor. It should be remembered that if sulfur trioxide is present in a reaction system, it immediately reacts with water. Apart from reactions (1) - (3), the following reaction also takes place:

$\mathrm{SO}_{3}+\mathrm{H}_{2} \mathrm{O} \rightarrow \mathrm{H}_{2} \mathrm{SO}_{4}$

The combined reactions (1) - (3) and (5) give the net reaction:

$\mathrm{CH}_{4}+\mathrm{SO}_{3}+\mathrm{H}_{2} \mathrm{O}+0.5 \mathrm{O}_{2} \rightarrow \mathrm{CH}_{3} \mathrm{OH}+\mathrm{H}_{2} \mathrm{SO}_{4}$

The claim promoted by Periana et. al ${ }^{3,4}$ and repeated by other authors $5,10-12$ that methane to methanol conversion can be carried out as waste free technology is false. The process needs sulfur trioxide and water and its by-product is sulfuric acid.

Following that, by-product of methane esterification is sulfuric acid (reaction (6)) obtained in the amount of 0.3 $\mathrm{kg}$ for every $100 \mathrm{~kg}$ of methyl bisulphate. This amount can be disregarded bearing in mind that the total mass of sulfuric acid $(100 \%)$ was $2.076 \mathrm{~kg}$. Therefore, it can be assumed that the mass of $\mathrm{H}_{2} \mathrm{SO}_{4}$ will not change after esterification.

Author has confirmed that it is possible to produce methanol from methyl bisulfate by adding water to the post-reaction mixture obtained as a result of esterification. It should also be added that hydrolysis is a reversible process ${ }^{13-15}$, which Periana et. al ${ }^{3,4}$ failed to point out. Therefore, the correct way of writing it can be given by: $\mathrm{CH}_{3} \mathrm{OSO}_{3} \mathrm{H}+\mathrm{H}_{2} \mathrm{O} \rightleftarrows \mathrm{CH}_{3} \mathrm{OH}+\mathrm{H}_{2} \mathrm{SO}_{4}$

Ester is hydrolyzed to alcohol in $100 \%$ if the amount of added water is such that sulfuric acid concentration amounts to $50 \mathrm{wt} \%$ or even less ${ }^{7}$.

A schematic diagram of methane to methanol conversion via methyl bisulphate hydrolysis in post-reaction mixture taking into account regeneration of by-products is presented in Figure 3.

Methane, oleum and catalyst are fed into the esterification reactor. The post- reaction liquid containing methyl bisulphate, oleum and the catalyst is directed to hydrolysis reactor and the gases to separation system. After separation methane is turned back to esterification reactor. Sulfur dioxides are directed to oxidation reactor. Regenerated sulfur trioxide is absorbed in concentrated sulfuric acid. In order to obtain the desired concentration of oleum $(25 \mathrm{wt}$ $\%$ of $\mathrm{SO}_{3}$ ) it is necessary to add „fresh" $\mathrm{SO}_{3}$. Following

Table 1. Mass balance of the methane esterification catalyzed by $\mathrm{PtCl}_{4}$, in order to obtain $100 \mathrm{~kg}$ of methyl bisulphate

\begin{tabular}{|l|c|c|c|c|c|c|}
\hline & $\begin{array}{c}\mathrm{CH}_{4} \\
{[\mathrm{~kg}]}\end{array}$ & $\begin{array}{c}\mathrm{SO}_{3} \\
{[\mathrm{~kg}]}\end{array}$ & $\begin{array}{c}\mathrm{H}_{2} \mathrm{SO}_{4} \\
{[\mathrm{~kg}]}\end{array}$ & $\mathrm{CH}_{3} \mathrm{OSO}_{3} \mathrm{H}[\mathrm{kg}]$ & $\begin{array}{c}\mathrm{SO}_{2} \\
{[\mathrm{~kg}]}\end{array}$ & $\begin{array}{c}\mathrm{CO}_{2} \\
{[\mathrm{~kg}]}\end{array}$ \\
\hline Before esterification & 116 & 692 & 2076 & 0 & 0 & 0 \\
\hline After esterification & 101 & 548 & 2076 & 100 & 57 & 0.07 \\
\hline
\end{tabular}




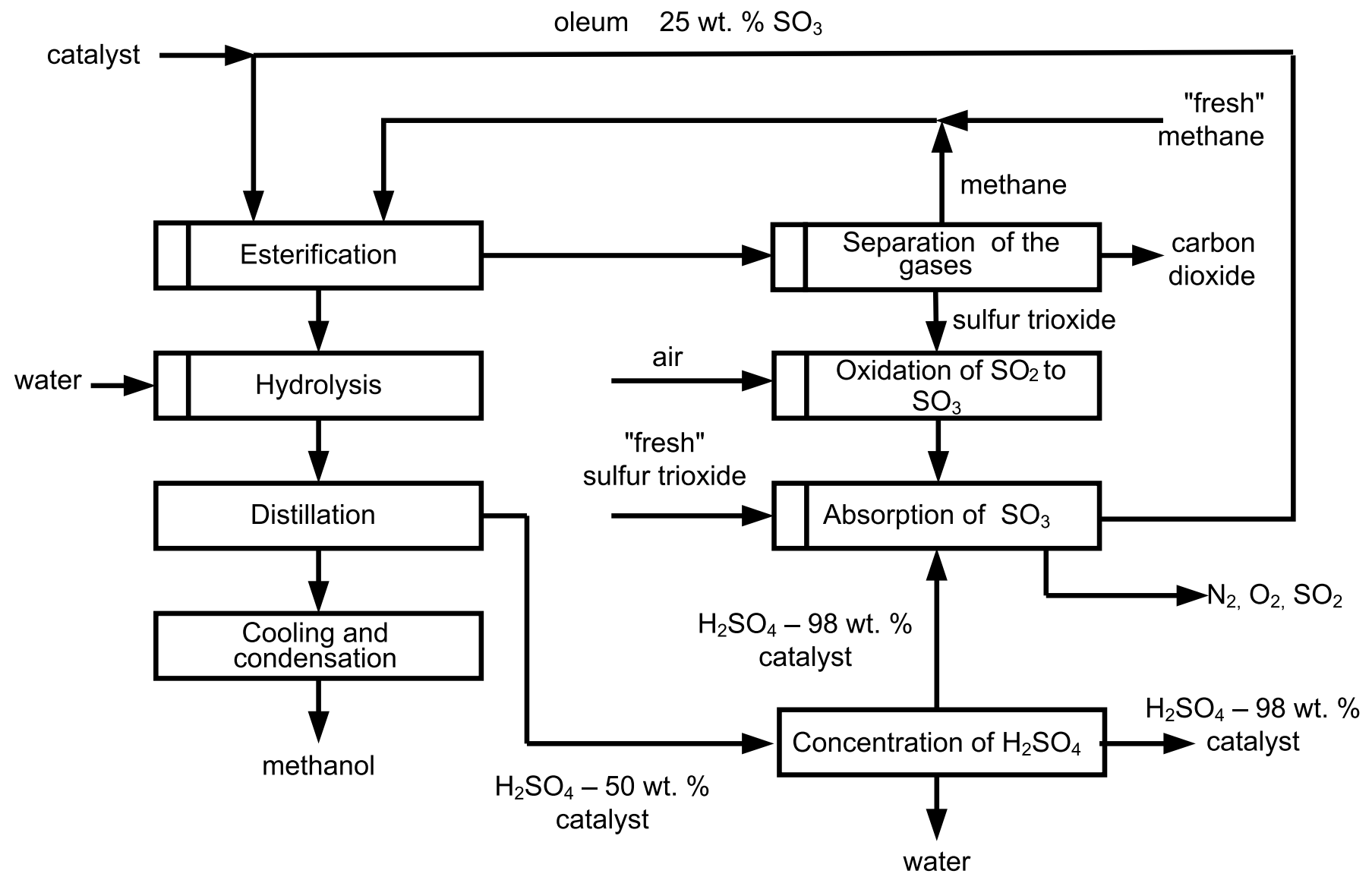

Figure 3. Schematic diagram of methane to methanol conversion via methyl bisulphate hydrolysis in post - reaction mixture

hydrolysis a solution of methanol and sulfuric acid (with $50 \%$ concentration) is obtained, which is then separated by means of distillation.

The acid diluted during hydrolysis is later concentrated. In hydrolysis reactor free sulfur trioxide reacts with water, which leads to production of additional sulfuric acid. This is also the reason that only a part of concentrated acid is returned to sulfur trioxide absorption and later to esterification. The excessive acid must therefore be carried off as by-product. Unfortunately, this acid contains the catalyst, so it is contaminated.

A mass balance for the above described process of obtaining methanol from methane according to the diagram shown in Figure 3 has been made. It is presented as Sankey diagram in Figure 4.

The data used for these calculations is the same as the balance data presented in Table 1 . The only difference is that the assumed mass of methanol (and not methyl bisulphate) as the final product was $100 \mathrm{~kg}$. The analysis of both hydrolysis and distillation showed that their efficiency reached $100 \%$.

As it can be seen in Fig. 4, the mass of water necessary for hydrolysis to be carried to the end is significant - it is $10.410 \mathrm{~kg}$ for every $100 \mathrm{~kg}$ of methanol. Sulfur trioxide is also to be found in the post- reaction solution left after esterification. During hydrolysis sulfur trioxide reacts with water. A certain amount of water is used not to dilute the acid, but quite contrary to increase its amount. The total mass of constituents after hydrolysis, which is directed to distillation is twice as large as the initial mass of esterification products, i.e. $19945 \mathrm{~kg}$ for every $100 \mathrm{~kg}$ of methanol.
This is undesirable, because an installation of a large size has to be used. Additionally, separation of methanol during distillation from such a mass of solution needs large amounts of energy. The same problems arise during concentrating sulfuric acid by means of water vaporization. After having concentrated acid to $96 \%$ (which incidentally is not necessary), its mass is $4168 \mathrm{~kg}$ for every $100 \mathrm{~kg}$ of methanol. The acid has trace amounts of contamination with the catalyst.

The analysis of the mass balance demonstrated that an addition of water to esterification post-reaction solution leads to many problems, such as: production of substantial amounts of excessive and contaminated sulfuric acid, large size of installation used for hydrolysis, distillation and acid concentration, considerable energy consumption. This kind of solution is not a favorable one. Any contact of oleum with water should be avoided in order not to produce additional sulfuric acid. An elimination of these problems is possible if methyl bisulphate is separated from esterification post- reaction solution before hydrolysis.

This can be achieved in a very simple way - through distilling off ester and its absorption in water. Unfortunately, during simple distillation sulfur trioxide is also produced, which reacts with water. As a result, additional amounts of sulfuric acid are produced ${ }^{7}$.

While investigating the possibilities of using membrane distillation it was found that at the initial stage of the process first sulfur trioxide and then methyl bisulphate are produced ${ }^{8}$. Conclusions can be drawn from this fact and distillation can be carried out as a two-stage process.

A schematic diagram is presented in Figure 5. Methane and oleum containing catalyst are fed into esterification reactor. Post- reaction gases are directed to separation 


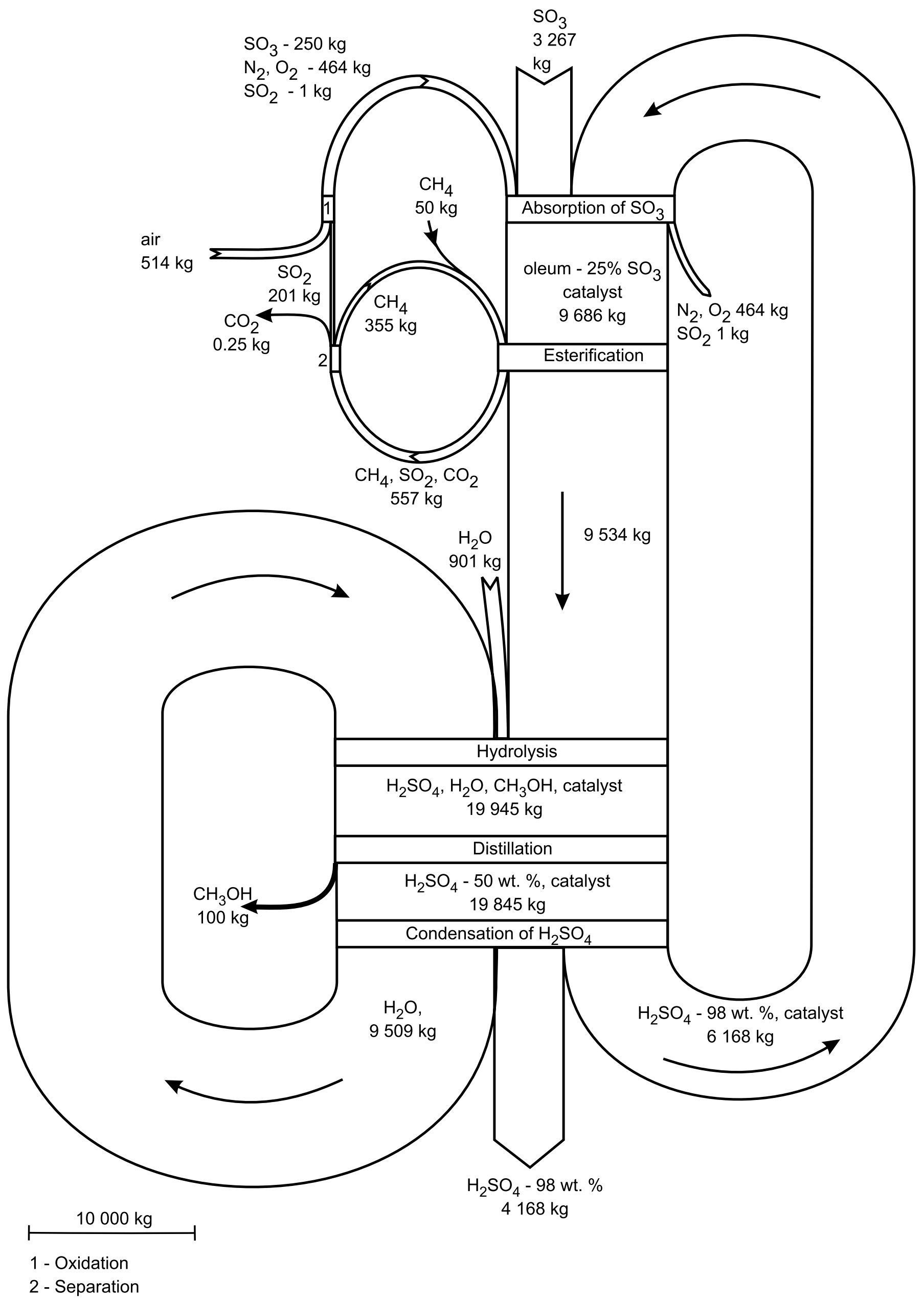

Figure 4. Sankey diagram for methane to methanol conversion via methyl bisulphate hydrolysis in post - reaction mixture 
oleum 25 wt. $\% \mathrm{SO}_{3}$

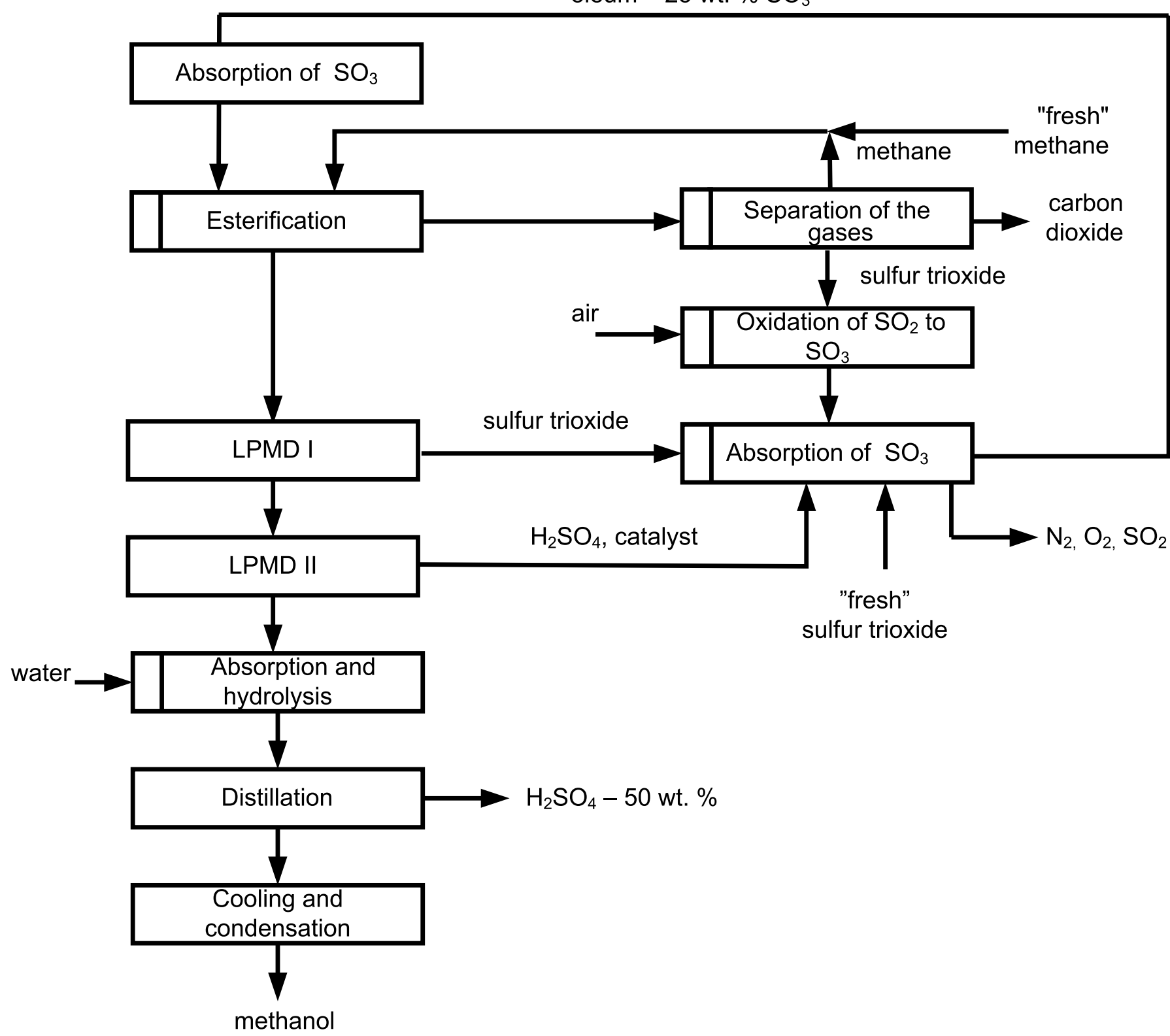

Figure 5. Schematic diagram of methane to methanol conversion with two stage membrane distillation

system. Regeneration of $\mathrm{SO}_{3}$ and oleum proceeds just as formerly (Fig. 3).

The post- reaction liquid containing methyl bisulphate, oleum and the catalyst undergoes a two-stage distillation. $\mathrm{SO}_{3}$ is produced first and is later absorbed in sulfuric acid. During the second stage of distillation methyl bisulphate is separated, which is later absorbed in water. The mass balance of the process is presented in the form of Sankey diagram in Fig. 6.

As it can be clearly seen in Fig. 6 this is the best solution. Sulfur trioxide has no contact with water used for hydrolysis and it is absorbed in sulfuric acid. There are two advantages of this kind of solution. The mass of water necessary for hydrolysis and the mass of additionally provided sulfur trioxide are smaller than in the earlier described methods. The mass of water is as small as only $362 \mathrm{~kg}$ for every $100 \mathrm{~kg}$ of methanol. In this case the production of redundant sulfuric acid with $50 \mathrm{wt} \%$ concentration is also significantly reduced - down to $612 \mathrm{~kg}$, which for $\mathrm{H}_{2} \mathrm{SO}_{4}$ with $96 \%$ concentration gives $319 \mathrm{~kg}$. This is owing to the fact that in this case redundant sulfuric acid is only produced in reaction (2). The amount of sulfur trioxide which must be additionally provided is 363 $\mathrm{kg}$ for every $100 \mathrm{~kg}$ of methanol. Although the application of two stage membrane distillation turned out to be the best solution, it is possible to use rectifying columns, which could give a similar effect.

\section{CONCLUSIONS}

The method of methyl bisulphate hydrolysis in oleum medium which was described by many authors as easy to conduct is in fact an unsuccessful one. It is necessary to separate ester from the post- reaction solution before hydrolysis and it is crucial to avoid sulfur trioxide's contact with water used for ester's hydrolysis. These conditions can be fulfilled using membrane distillation. Any other method could be used for ester separation e.g. rectification. In this method the catalyst circulates in the system together with a part of $\mathrm{H}_{2} \mathrm{SO}_{4}$ and the sulfuric acid produced as a result of reaction (2) is free from contamination and can later be used for other purposes. 


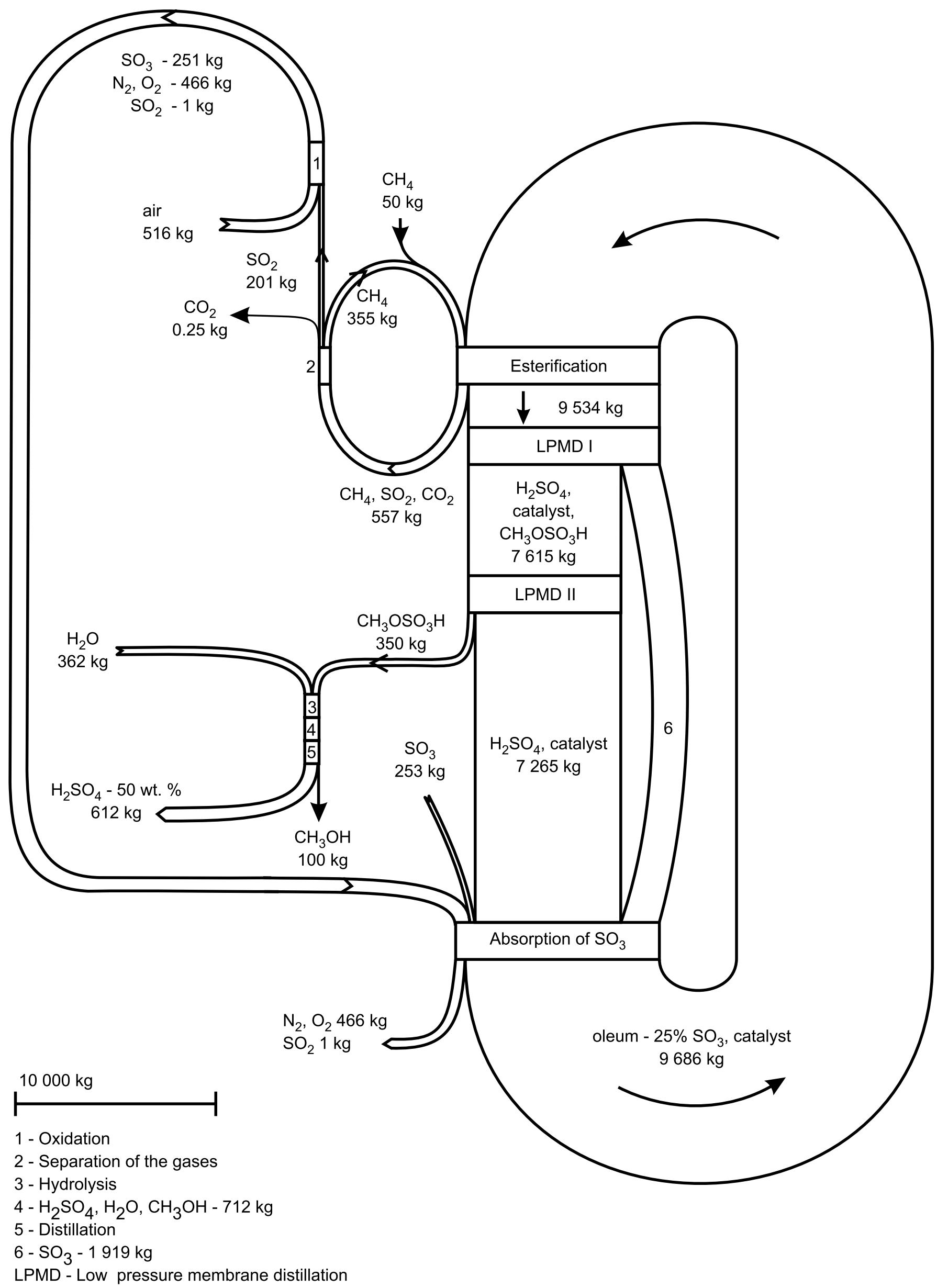

Figure 6. Sankey diagram of methane to methanol conversion with two stage membrane distillation 
Regardless of any possible modifications of the above described methods redundant sulfuric acid will always be produced during ester hydrolysis. Production of methanol from methane using this method can only be done when it is combined with producing other substances, which needs using $\mathrm{H}_{2} \mathrm{SO}_{4}$. The process can be applied in chemical plants manufacturing artificial fertilizers, whose production needs both methane and sulfuric acid used as raw materials to make other products.

\section{LITERATURE CITED}

1. Bone, W. A. \& Wheeler, R. V. (1902). The slow oxidation of methane at low temperatures. J. Chem. Soc., Trans., 81, 535 - 548. DOI: 10.1039/CT9028100535.

2. Periana, R. A., Taube, D. D., Taube, H. \& Eritl, E. R. (1992). WO /1992/014738.

3. Periana, R. A., Taube, D. J., Evitt, E. R., Löffler, D. G., Wentrcek, P. R., Voss, G. \& Masuda, T. (1993). A mercurycatalyzed high-yield system for the oxidation of methane to methanol. Science, 259, 340 - 343.

4. Periana, R. A., Taube, D. J., Gamble, S., Taub,e H., Satoh, T. \& Fujii H. (1998). Platinum catalysts for the highyield oxidation of methane to a methanol derivative. Science, 280, $560-564$.

5. Gang, X., Zhu, Y., Birch, H., Aage, H., Hjuler, A. \& Bjerrum, N. (2004). Iodine as catalyst for the direct oxidation of methane to methyl sulfates in oleum. Appl. Catal. 261, 91 - 98. DOI: 10.1016/j.apcata.2003.10.039.

6. Michalkiewicz, B., Kałucki, K. \& Sośnicki, J. G. (2003). Catalytic system containing metallic palladium in the process of methane partial oxidation. J. Catal. 215, 14 - 19. DOI: 10.1016/S0021-9517(02)00088-X.

7. Michalkiewicz, B. (2006). Conversion methods of methyl bisulfate dissolved in oleum into methanol. Pol. J. Chem. Technol. 8, $68-69$.

8. Michalkiewicz, B. Ziebro, J. \& Tomaszewska, M. (2006). Preliminary investigation of low pressure membrane distillation of methyl bisulphate from its solutions in fuming sulphuric acid combined with hydrolysis to methanol. J. Membrane Sci. 286, 223 - 227. DOI: 10.1016/j.memsci.2006.09.039.

9. Malin, K. M. (1975). Sufuric acid. WNT, Warszawa.

10. Gang, X., Zhu, Y., Birch, Zhu, Y Aage, H., Hjuler, A. \& Bjerrum, N. (2000). Direct oxidation of methane to methanol by mercuric sulfate catalyst. J. Catal. 196, 287 292. DOI: $10.1006 /$ jcat.2000.3051.

11. Wolf, D. (1998). High yields of methanol from methane by $\mathrm{c}-\mathrm{h}$ bond activation at low temperatures. Angew. Chem. 37, $3351-3353$.

12. Taylor, C. E., Anderson, R. \& Noceti, R. P. (1997). Activation of methane with organopalladium complexes. Catal. Today. 35, 407 - 413. DOI: 10.1016/S0920-5861(96)00213-1.

13. Lewis, H.F., Mason, O. \& Morgan, R. (1924). Methylations hydrolysis of dimethyl sulfate. Ind. Eng. Chem. $16,811-812$.

14. Batts, B.D. (1966). Alkyl hydrogen sulphates. Part I. Hydrolysis in moist dioxan solution. J. Chem. Soc. (B), 547 $-551$.

15. Batts B.D. (1966). Alkyl hydrogen sulphates. Part II. Hydrolysis in aqueous acid solution J. Chem. Soc. (B), 551 -555 . 